siderable excavation in the lungs. In such subjects, not very frequently met with, recoveries do sometimes indubitably occur; the treatment consisting of an almost entire restriction to the most stimulating animal diet; of salt largely administered at every meal ; of quinine and preparations of iron; and of lotions of spirit of wine and tincture of iodine applied to the surface of the chest. To such subjects sea-air is especially beneficial. I have known the audible evidences of consumption to disappear and reappear in individuals visiting the East Indies, the disease at last proving fatal, as in one instance very lately, apparently in consequence of the individual having prolonged his stay in England longer than usual: in such subjects I have known a well-marked excavation continue for many years, apparently stationary. The rapid progress of consumption in more irritable subjects, in whom the pulse is 100 or 120, is in many instances, I have reason to believe, as much attributable to the highly absurd and reprehensible practice of bleeding to arrest hæmoptysis, as to the unresisted progress of tubercular disease; chronic dis. ease invades the system when the vital powers are depressed, and always acquires growth and rapidity from exhaustion of the vital and opposing force; bleeding for bremoptysis in subjects suffering from tuherculous cachexia, may be denominated fashionable homicide. I am at present acquainted with many delicate individuals who have been expectorating blood, at intervals, for several years ; I am convinced that every one of them would be destroyed by even a moderately large bleeding; why should such panic be excited by ordinary hæmoptysis as to confound all common sense and sober judgment? The hæmoptysis may doubtless be arrested by bleeding, but though the triumph of arresting it be great the patient is merely placed upon his legs to stagger to the grave. In nineteen cases out of twenty the hæmorrhage will cease by judicious treatment, without the adoption of the desperate expedient of bleeding, which, though it continue for days or weeks, a natural hæmorrhage is far more easily borne than detraction of blood by the lancet; calmly and judiciously advise and administer, and seldom will dangrer or difficulty result from the mere hæmoptysis, though the patient may ultimately die from the natural progress of the disease. With every sentiment of respect, I am, Sir; \&c.

April 5, 1843

Anthropos.

THE PLACENTA.

To the Editor of THE LANCET.

SIR,-"Ele," in last week's LANCET, page 45 , seems to think that the only addition that is made to the foetus through the placenta is by the process of aeration, which he supposes to occur, as in the Inngs, by the permeability of the capillary tissue. Also that there is no communication between the fcetal and the maternal capillaries, in the placenta; and this appears to be still the general opinion of physiologists. But can "Ele," or any other disputant, go a little farther and say how the addition is made of albumen, or fibrine, for the growth of the foetus? Do they imply that these are reduced in the placenta to one ultimate state, as in the general nutrition, and then are taken up by permeation into the foetal vessels? If that were the case, the placenta would have more to do than its nerves would indicate; and, allowing, for a moment, that oxygen may be so received, yet there are no lymphatics in the funis to carry albumen or fibrine, and the venous capillaries are not $a b$ sorbent vessels, but form the direct continuations of arterial capillaries. Viviparous animals may at tirst, like the oviparous, form their own blood; for at first they are alike in condition. Bnt during the latter and greater period of utero-gestation, the viviparous animal directly borrows the maternal circulation for the use of the lungs and digestive organs. Of this I am as certain as of any other fact in physiology, for I have proved the direct course by injections. The old theory was founded on the results of an imperfect method of injecting; and the only proper opportunities are not to be obtained every day. A week or two back THE LANCET contained the opinion of a French physiologist that a solution of the acetate of ammonia, and certain other salts, facilitaled the injection of capillary vessels. I have shown that the alkalies, soda, and potass, have this relaxing effect, as every one may guess who has cut his face while shaving, when the smallest cut bleeds remarkably from the effect of the soap, and if the injection be one which sets when cold, so much the better.

But there are other practical facts, which all experienced obstetricians have noticed as well as myself, and which are conclusive as to the capillary courses in the placenta. In violently quick labours the child and placenta are occasionally expelled together, and the free surface of the latter always bleeds fastly in those cases, but the bleeding ceases when the cord is tied, or when it ceases to pulsate.

I am in the habit of tying only one ligature on the funis instead of two, and cutting beiween them. I have done this, under the impression that the blood which flows from the free end of the funis diminishes the bulk of the placenta (if the latter be separated from the walls of the nterus), causing its expulsion to be easier. This plan has given me the opportunity of observing (as I find it has others) that when the placenta has not separated from the uterus, the cord some- 
times bleeds freely; and that when it has separated, very little blood flows. But I find that tying this free end of the funis helps the placenta to separate where it has not done so.

In entertaining the old notion of the placental capillary courses, which I have quite disproved by experimental injections, much must necessarily be overlooked in this branch of physiology. I remain, Sir, yours obediently,

Kennington, April 8, 184 :.

R. Stevens.

Femoral Hernia.-At a late meeting of the Iondon Medical Society, Mr. PILcher, the president, detailed some particulars of a case of femoral hernia which terminated fatally, and which was observed during life by a very prominent condition of the os pubis, and an exostosis of the upper part of the thigh-bone. The usual symptoms of hernia were unequivocal, and a very careful examination of the parts in which hernia is usually situated was made. No kind of tumour could be detected in the femoral region. After death, however, a small femoral hernia was found, and it was then discovered that the small portion of sut which was strangulated had lain in a hollow formed by the pubis and exostosis, as mentioned above.

CASE OF YOLVULUS REMOVED BY INJECTIONS.

At the same meeting Mr. PILcher also related a case of volvulus in a child to which he was called after all the usual remedies for the removal of the disease had been ineffectually employed. Recollecting the beneficial effect of an injection in a case of this kind some, years before, he recommended that as much thin gruel as could be thrown up into the bowel should be injected by the common injection-syringe. The quantity thrown up was very large, and the bowels were much distended by it. The effect was almost immediate and quite decided, the obstruction gave way, and the patient recovered.

InTEsTinal OBSTRuCtion.-The London Medical Society was occupied at its meeting on the 3rd April, with a discussion on obstruction in the intestinal canal, and addressed itself chiefly to the question as to whether we possessed sufficient information on this subject to be always able to determine on what cause the obstruction immediately depended. Could we unequivocally declare the presence of intus-susception; or could we pronounce the constipation to arise from mere accumulation of fæces, or from the absence of bile in sufficient quantity to produce the peristaltic action of the lintes. tines? The discussion was desultory, and could not be made available for a report.

\section{TyIr TANCTET.}

London, Saturday, April 15, 1843.

ThE great military and political events which the importation of opium into China, or, rather, the probibition of such importation, has produced, would not qualify the "opium question" to receive notice in the pages of The Lancet. Since, however, that question has a very important relation to bygiene, we propose to institute a fair examination into its principal points, a course which we feel the more inclined to adopt because the evils that really result from the abuse of opium have been greatly exaggerated, while a very false political view of the subject is entertained in some highly respectable quarters.

And, first, with regard to the actual amount of evil resulting from the consumption of opium as an article of luxury. This is generally stated and believed to be infinitely greater than that arising from habitual intoxication with alcoholic liquors. We may observe, in limine, that although the constant use of substances which are calculated to induce an unnatural state of the nervous system is, in most instances, highly injurious, the pernicious effects of such substances have generally been over.rated. Now this is in itself an evil, because where the simple truth affords a suficient condemnation of any prevalent practice, the smallest exaggeration or dis" tortion of that truth tends merely to weaken the case by placing a certain amount of experience in opposition to it. For example: dram-drinking is one of the most formidable evils that beset this country, and produces truly deplorable effects on the minds, bodies, and estates of a large portion of the popula. tion. But if it be asserted, as it often is, that the invariable result of the practice is an utter prostration of every power of body and mind, followed by premature senility and death, hundreds of men who have been dram-drinkers from their youth upwards, but 